\title{
Utilizing Single-Crystal X-ray Diffraction to Determine Unusual Structural Trends within Group 15 Triamido Complexes
}

\section{K Marczenko ${ }^{1}$, S Chitnis ${ }^{1}$ \\ ${ }^{1}$ Dalhousie University, Department of Chemistry kt991187@dal.ca}

We recently used a trianionic pincer ligand to prepare group 15 triamido complexes that were characterized in the solid and solution phases. In this homologous series, the central element can adopt either a bent (VSEPR) or planar (non-VSPER) geometry. This talk will discuss the change in structural preferences descending the group, the consequence of structure on the electronic environment at the metal center, and why sometimes the structured determined by X-ray crystallography is not retained in solution!

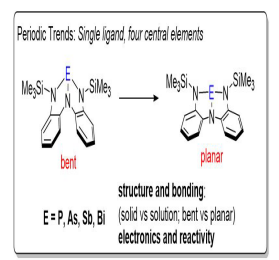

Figure 1

Acta Cryst. (2020). A76, a156 